Adrenocortical suppression presenting with agitated depression, morbid jealousy, and a dementia-like state

SIR: The most likely explanation of the severe confusional state in this lady with suppression of adrenocortical function (Journal, December 1991, $159,870-872$ ) is that she was suffering from intermittent low blood sugar. I described a somewhat similar problem 30 years ago with Isaac Marks (Cohen \& Marks, 1961). One would like to know the figure for the blood sugar reading, whether several readings were made, and whether, in particular, repeated measurements of the fasting blood sugar were made. It would also be of interest to know why no attempt was made to restore the function of the endocrine system. This might have been worth trying, and preferable to life-long treatment with prednisolone.

Cohen, S. I. \& MArks, I. M. (1961) Prolonged organic psychosis with recovery in Addison's disease. Journal of Neurology. Neurosurgery and Psychiatry. 24, 366-368.

London Hospital Medical College

Samuel I. Cohen

3rd Floor, Alexandra Wing

Turner Street, London EI 2AD

\section{Community care and the need for hospital beds}

SIR: Lawrence et al (Journal, September 1991, 159, $334-340$,) conclude from their data that "there is a bed-rock of illness which will always need inpatient care however comprehensive the community resources". Few would quibble with this, but when they suggest that this bed-rock level has already been reached, and use their data to support it, their paper acquires much greater significance. The implication is that present psychiatric bed levels in the country constitute a minimum acceptable level and that any further reduction would lead to poorer care.

There are several reasons for thinking that this conclusion might not be correct. The figures certainly show that the mean bed occupancy at Kidderminster Hospital between 1978 and 1985 was virtually no different from that of Powick Hospital between 1971 and 1978, and this suggests no change in bed demand following the move from a traditional (rural) mental hospital to a typical (urban) district hospital psychiatric unit. Our main concern is with the assumption that Kidderminster Hospital was practising community care. Although more 'community' resources were available in Kidderminster than in the other two hospitals (primarily in numbers of community nurses and day hospital places), this does not mean that community psychiatry was practised. Where is the information showing greater liaison with general practitioners, assessment of patients at home independent of domiciliary visits, growth of multidisciplinary community teams and liaison with voluntary medical health agencies? We suspect that none of these took place, as the authors admit that "there was no change in service pattern" following the introduction of the new service.

The paper would have been more appropriately titled "Does a psychiatric unit in a district general hospital reduce the need for psychiatric beds?" and the answer is "No, at least not in Worcester", although a more positive answer has been given elsewhere (Jones et al, 1980). We as psychiatrists are in danger of being made to look fools if we persistently ask for more resources in order to practise community psychiatry and then, when we get them, continue on our way exactly as we did before. The consequence is a more expensive psychiatric service with no change in service patterns. Other figures suggesting that well-endowed hospitals with more community provision do not necessarily use fewer beds (Hirsch, 1987) could be cited in support of the Worcester findings but may also suffer from service delivery remaining static.

The transfer of psychiatric services to district general hospital sites may not in itself constitute the best model for future development. When care is practised with proper respect for the much mutilated adjective 'community', there can be a dramatic fall in the use of hospital beds made up by fewer and shorter admissions (Tyrer et al, 1989, 1990; Williams \& Balestrieri, 1989). Until this practice becomes the norm it would be premature to regard the number of psychiatric beds used currently or the existing ratio of 19:1 in hospital/community resources as any sort of baseline.

Hirsch, S. R. (1987) Planning for bed needs and resource requirements in acute psychiatry. Bulletin of the Royal College of Psychiatrists, 11, 398-407.

Jones, R., GoldBerg, D. \& Hughes, B. (1980) A comparison of two different services treating schizophrenia: a cost-benefit approach. Psychological Medicine. 10, 493-505.

TYRER, P., TURNER, R. \& JoHNSON, A. L. (1989) Integrated hospital and community psychiatric services and use of inpatient beds. British Medical Journal, 299, 298-300.

Ferguson, B. \& WADSWORTH, J. (1990) Liaison psychiatry in general practice: the comprehensive collaborative model. Acta Psychiatrica Scandinavica, 81, 359-363.

Williams, P. \& Balestrieri, M. (1989) Psychiatric clinics in general practice: do they reduce admissions? British Journal of Psychiatry, 154, 67-71.

Early Intervention Service

Peter Tyrer

Unit 5, 1-31 Elkstone Road

London W10

Stonebridge Mental Health Team

Brian Ferguson

Nottingham NG3 $2 F H$ 